\title{
Characterization of blood donors and non-blood donors in Germany using an online survey
}

\author{
Benita Stock ${ }^{1} \cdot$ Luis Möckel $^{2}$ (1)
}

Received: 29 September 2020 / Accepted: 8 February 2021 / Published online: 2 March 2021

(c) The Author(s) 2021

\begin{abstract}
Objectives of this study were to analyze characteristics influencing blood donation status, to identify anxieties and reasons for (non-)blood donation, and potential channels for future blood donation campaigns. A random population from Germany was interviewed using the online survey tool SoSci Survey. The access link to the questionnaire was distributed via snowball system and the Bavarian Red Cross. Statistical analysis was performed to identify factors influencing blood donation status. A total of 682 participants (27.3\% blood donors) with a mean age of 33.4 and a standard deviation (SD) of 12.0 years were included into the analysis. Strongest factor associated with being blood donor was having a blood donor within family and friends (Odds ratio [OR]: 5.05 [95\% confidence interval [95\% CI]: 2.63; 9.70]; $p \leq 0.001$ ), whereas having anxiety related to blood donation was the strongest factor for being non-blood donor (OR: 0.11 [95\% CI: $0.05 ; 0.21] p \leq 0.001$ ). Other factors significantly influencing blood donor status were age, health-related quality of life, knowledge on blood donation, being an organ donor and having pre-conditions. Main anxieties avoiding blood donation were fear of physical consequences, and fear of the injection needle. Most frequently mentioned channels which should be used for blood donation campaigns were Instagram and free TV. Involving blood donors into campaigns to recruit new blood donors from their personal environment and to focus campaign content on physical benefits of blood donations might help to recruit new blood donors. In addition, running campaigns stronger on channels such as Instagram might increase their scope.
\end{abstract}

Keywords Blood donation $\cdot$ Blood demand $\cdot$ Transfusion $\cdot$ Health service $\cdot$ Medical aid

\section{Introduction}

Blood donations are essential for different health care services such as the treatment of emergency patients and several kinds of surgeries. Between 2010 and 2019 the number of blood donations decreased by $12 \%$ from 7.5 Mio. to 6.6 Mio. in Germany [1]. Previous publications have reported concerns on the maintenance of blood supply and potential blood shortages [2,3]. A recent study by Greinacher et al. (2017) conducted in a north-eastern region of Germany showed a decline in blood donations in younger age groups between 2005 and 2015. Donation rates

Luis Möckel

1.moeckel@hs-doepfer.de

1 HSD Hochschule Döpfer GmbH, University of Applied Sciences Regensburg, Prüfeninger Straße 20, 93049 Regensburg, Germany

2 HSD Hochschule Döpfer GmbH, University of Applied Sciences Cologne, Waidmarkt 3 \& 9, 50676 Cologne, Germany per 1,000 inhabitants decreased by $10.6 \%$ (140.5 to 125.6) and $28.1 \%$ (103.0 to 74.1 ) in the populations aged $18-30$ and 31-40 years, respectively. In contrast, rates increased in the populations aged $51-60$ years ( 75.5 to 88.4 ) by $17.1 \%$ and $61-69$ years (22.5 to 51.2$)$ by $127.5 \%$ [4]. Nevertheless, the authors discussed a further reduction in blood donations when the population aged 51-60 years is not able to donate blood anymore [4]. In addition, a prediction for the southern German region Baden-Wuerttemberg indicates a decrease in blood donation of $11 \%$ by 2030 compared to 2007, and a concurrent increase in blood product consumption of $10 \%$ in tertiary care centers and up to three times in primary care centers [5].

For the planning of blood donation campaigns and to stop the reduction in blood donations it is key to understand factors influencing blood donation status. A study with 542 undergraduate students in Hong Kong indicated that among other factors, gender, age, being an organ donor, knowledge on blood donation, and the self-reported health status were significantly associated with blood donation status [6]. A 
second study performed with 5640 (non-)blood donors in Germany showed that being blood donor is related to characteristics such as being female, of younger age, and more satisfied with the own health as well as being helpful [7].

But to the best of our knowledge currently missing for Germany are information on how exercise behavior, anxieties, education on blood donation, and especially how family and friends are influencing the blood donation status. Furthermore, it is key to understand which are preferred channels of (non-)blood donors in terms of promotion of blood donation campaigns. Therefore, the aim of this study was to characterize (non-)blood donors in Germany to gather further information on factors affecting blood donation status. Additionally, to understand reasons and anxieties influencing blood donation status and channels which could be used to promote future blood donation campaigns.

\section{Methods}

\subsection{Study design}

This study was a survey study on blood donation of a random population in Germany conducted between June 19th to August 28th, 2020. The survey was performed using the SoSci Survey online tool [8] and the link to access the survey was distributed via snowball sampling. Therefore, participants were instructed to distribute the link to the survey within their social environment. In addition, the access link was provided to the Bavarian Red Cross (BRK), a blood donation service, to increase the number of blood donors in this study. The participation in this study was voluntary, the participants did not receive any compensation and no stigmatizing questions were asked.

\subsection{Questionnaire development}

For the development of the questionnaire, we conducted qualitative interviews with a total of 13 volunteers of which 5 were non-blood donors, 5 were blood donors and 3 were employees of the Bavarian Red Cross. Questions developed based on the information gathered in the qualitative interviews were then pre-tested with a subset of 22 volunteers and if necessary, adjustments of the questions were performed.

The survey consisted of questions on age, gender, current blood donor (options: yes/no), age at first blood donation and organ donor (options: yes/no). To be mentioned here is that participants were only classified as current blood donors, if they donated blood at least once within the last 18 months. In addition, we asked for pre-conditions (options: yes/no) and to rate the own health-related quality of life ( $\mathrm{HrQoL})$. The item used for measuring the HrQoL was based on the
EQ-VAS, by using a scale of 0, worst imaginable HrQoL, to 100, best imaginable HrQoL [9]. Pre-conditions were defined as any existing cardiovascular, pulmonary, endocrinological, infectious or cancerous disease. Study participants were also asked, if they have blood donors within family and friends (options: none, family, friends, family and friends), their reasons for donating or not donating blood and if they received any education on blood donation in school, vocational training or university. Additionally, participants were asked to rate their knowledge on blood donation by using a scale of 0 , not at all informed, to 100 , fully informed. Further questions were on anxieties related to blood donation and if they think that blood donations are associated with any physical benefits or disadvantages (options: none, benefits, disadvantage). Finally, we asked on weekly exercise behavior of participants with the possibility to choose no exercise, at least $2 \mathrm{x}$ for 30 min per week, at least $3 \mathrm{x}$ for 30 min per week or at least $5 \mathrm{x}$ for $30 \mathrm{~min}$ per week.

\subsection{Statistical analysis}

Questionnaires which were finished by at least $85 \%$ and in which the question if the participant is current blood donor was answered, were included into the study. For description of characteristics of study participants, percentage of males, participants with pre-condition, and organ donors were calculated for the total population, blood donors and non-blood donors, respectively. In addition, means and corresponding standard deviations (SD) were calculated for age and HrQoL for all three populations, and mean age at first blood donation for current blood donors.

To identify variables characterizing blood donors and non-blood donors, we applied univariate analysis. Associations between blood donation status and age, HrQoL or knowledge on blood donation were analyzed using logistic regression model, respectively. If being blood donor was associated with the following variables, gender, pre-conditions, being an organ donor, exercise behavior, blood donors within family / friends, anxiety related to blood donation, knowledge on physical benefits / disadvantages from blood donation, and receiving education on blood donation was analyzed using Pearson's chi-squared or Fishers' exact test, respectively. For analyses using Pearson's chi-squared or Fishers' exact test, subgroup(s) of the variables were compared to one reference subgroup, which was the female population in terms of gender and the populations which have chosen the answer option no / none for the other mentioned variables. For each variable odds ratio (OR) and corresponding 95\% confidence intervals (95\% CI) for being blood donor were calculated and a p-value of 0.05 was considered statistically significant. Statistical analysis was performed using JASP software package [10]. 
Table 1: Characteristics of study participants

\begin{tabular}{|c|c|c|c|}
\hline \multirow[t]{2}{*}{ Characteristics } & \multicolumn{2}{|l|}{ Blood Donors } & \multirow[t]{2}{*}{ Total $(n=682)$} \\
\hline & Yes $(n=682)$ & No $(n=496)$ & \\
\hline Gender male - $\mathrm{n}(\%)$ & $63(33.9 \%)$ & $130(26.2 \%)$ & $193(28.3 \%)$ \\
\hline Age - mean (SD) & $31.8(10.8)$ & $33.9(12.4)$ & $33.4(12.0)$ \\
\hline Organ donors - $\mathrm{n}(\%)$ & $133(71.5 \%)$ & $260(52.4 \%)$ & $393(57.6 \%)$ \\
\hline $\begin{array}{l}\text { Age at first blood } \\
\text { donation - mean (SD) }\end{array}$ & $21.8(6.1)$ & - & - \\
\hline $\begin{array}{l}\text { With precondition - } \mathrm{n} \\
(\%)\end{array}$ & $26(14.0 \%)$ & $138(27.8 \%)$ & $164(24.1 \%)$ \\
\hline HrQoL - mean (SD) & $80.1(16.1)$ & $72.9(19.9)$ & $74.8(19.2)$ \\
\hline
\end{tabular}

\section{Results}

\subsection{Characteristics of study participants}

A total of 682 participants with a mean age of 33.4 and SD of 12.0 years were included into the study (Table 1). Of these, 186 participants were blood donors (mean age 31.8 SD 10.8 years), and 496 were non-blood donors (mean age 33.9 SD 12.4 years). Percentage of male participants was $28.3 \%, 33.9 \%$ and $26.2 \%$ for total population, blood donors and non-blood donors, respectively. Number of organ donors was higher in blood donors (71.5\%) compared to non-blood donors (52.4\%), whereas the number of participants with pre-conditions was higher in non-blood donors $(27.8 \%$ vs. $14.0 \%)$. Mean HrQoL was 80.1 (SD 16.1) in blood donors, 72.9 (SD 19.9) in non-blood donors and 74.8 (SD 19.2) in total population. The mean age of current blood donors at first blood donation was 21.8 (SD 6.1) years.

\subsection{Sociodemographic factors and knowledge influencing blood donors}

Full analysis of variables characterizing blood donors and non-blood donors is shown in Table 2. The analysis indicated that increasing age was associated with a significant lower probability of being blood donor (OR: 0.99 [95\% CI: 0.97; $1.00] p=0.043)$, whereas increasing knowledge on blood donation (OR: 1.04 [95\% CI: 1.03; 1.05] $p \leq 0.001$ ) and increasing HrQoL (OR: 1.02 [95\% CI: $1.01 ; 1.03] p \leq 0.001$ ) were significantly associated with a higher likelihood of being blood donor, respectively.

Organ donors (OR: 2.78 [95\% CI: $1.58 ; 3.28] p \leq 0.001$ ) and study participants who know that blood donation is associated with physical benefits (OR: 3.07 [95\% CI: 2.12; 4.45] $p \leq 0.001$ ) indicated significantly higher numbers of blood donors, respectively. In addition, blood donors within family (OR: 2.82 [95\% CI: $1.32 ; 6.03] p=0.006$ ) or friends (OR: 2.44 [95\% CI: 1.24; 4.76] $p=0.008$ ) was also significantly associated with higher proportion of blood donors. Nevertheless, strongest factor for the probability of being blood donor was blood donors within family and friends (OR: 5.05 [95\% CI: 2.63; 9.70] $p \leq 0.001$ ). In contrast, participants with pre-conditions were less frequent blood donors compared to participants without pre-conditions (OR: 0.42 [95\% CI: $0.27 ; 0.67] p \leq 0.001$ ). In particular, participants with anxiety related to blood donation were significantly less likely to be blood donors compared to participants without anxiety (OR: 0.11 [95\%: $0.05 ; 0.21] p \leq 0.001$ ) (Table 2).

Gender, education on blood donation in school, at vocational training or university as well as the number of exercises per week indicated no significant impact on

Table 2: Factors influencing blood donation status

\begin{tabular}{|c|c|c|c|}
\hline Variable & Subgroups & OR $(95 \% \mathrm{CI})$ & p-Value \\
\hline Age & By one year age increase & $0.99(0.97 ; 1.00)$ & $p=0.043$ \\
\hline HrQoL & By one unit HrQoL increase & $1.02(1.01 ; 1.03)$ & $p \leq 0.001$ \\
\hline Knowledge in blood donation & By one unit knowledge increase & $1.04(1.03 ; 1.05)$ & $p \leq 0.001$ \\
\hline Gender & (1) Female, (2) Male & (1) Reference, (2) $1.43(1.00 ; 2.06)$ & $p=0.051$ \\
\hline Pre-conditions & (1) No, (2) Yes & (1) Reference. (2) $0.42(0.27 ; 0.67)$ & $p \leq 0.001$ \\
\hline Organ donor & (1) No, (2)Yes & (1) Reference, (2) 2,78 (1.58; 3.28) & $p \leq 0.001$ \\
\hline Exercises / week & $\begin{array}{l}\text { (1) None, (2) Min. 2x } 30 \mathrm{~min} / \\
\text { week, (3) Min. 3x } 30 \mathrm{~min} / \text { week, } \\
\text { (4) Min. 5x } 30 \mathrm{~min} / \text { week }\end{array}$ & $\begin{array}{l}\text { (1) Reference (2) } 1.25(0.83 ; 1.89) \text {, } \\
\text { (3) } 1.25(0.79 ; 1.99),(4) 0.99 \\
(0.55 ; 1.80)\end{array}$ & $\begin{array}{l}\text { (2) } p=0.292 \\
\text { (3) } p=0.347 \text {, (4) } p=0.984\end{array}$ \\
\hline Blood donors within family / friends & $\begin{array}{l}\text { (1) None, (2) Family, (3) Friends, } \\
\text { (4) Family and friends }\end{array}$ & $\begin{array}{l}\text { (1) Reference, (2) } 2.82(1.32 ; 6.03) \text {, } \\
\text { (3) } 2.44(1.24 ; 4.76), \text { (4) } 5.05 \\
\text { (2.63; 9.70) }\end{array}$ & $\begin{array}{l}\text { (2) } p=0.006,(3) \\
p=0.008,(4) p \leq 0.001\end{array}$ \\
\hline Anxiety & (1) No, (2) Yes & (1) Reference, (2) $0.11(0.05 ; 0.21)$ & $p \leq 0.001$ \\
\hline $\begin{array}{l}\text { Physical benefits /disadvantages } \\
\text { from blood donation }\end{array}$ & $\begin{array}{l}\text { (1) None, (2) Yes, benefits, (3) Yes, } \\
\text { disadvantages }\end{array}$ & $\begin{array}{l}\text { (1) Reference, (2) } 3.07(2,12 ; 4,45) \text {, } \\
\text { (3) } 0.63(0.30 ; 1,33)\end{array}$ & (2) $p \leq 0.001$, (3) $p=0.224$ \\
\hline Education on blood donation & $\begin{array}{l}\text { (1) None, (2) In school, (3) Dur- } \\
\text { ing vocational training, (4) At } \\
\text { university }\end{array}$ & $\begin{array}{l}\text { (1) Reference, (2) } 1.63(0.83 ; 3.22) \text {, } \\
\text { (3) } 1.16(0.55 ; 2.44), \text { (4) } 1.49(0.24 \text {; } \\
6.77)\end{array}$ & $\begin{array}{l}\text { (2) } p=0.155,(3) \\
p=0.693,(4) p=0.699\end{array}$ \\
\hline
\end{tabular}


the blood donation status (Table 2), respectively. But to be mentioned here is that male participants were nonsignificantly more likely to be blood donors (OR: 1.43 [95\% CI: $1.00 ; 2.06])$ with a close to significance $p$-value of 0.051 .

\subsection{Personal reasons for blood donation}

Blood donors mentioned helpfulness (63.78\%), professional background $(24.41 \%)$, own physical health $(3.24 \%)$, and tragedy within the personal environment $(3.24 \%)$ as most frequent reasons to donate blood (Fig. 1). In contrast, not fulfilling the inclusion criteria $(22.89 \%)$, other $(19.08 \%)$, lack of time (17.87\%), lack of motivation (13.05\%), and anxiety $(12.65 \%)$ were main causes to not donate blood (Fig. 2a). Most frequently mentioned reasons among other were pregnancy or breastfeeding (women only: 15.92\%) and own health (both gender: $40.00 \%$ ). Fear of physical consequences after blood donation $(20.85 \%)$, injection needle $(17.00 \%)$ and no trust in blood sampling personal $(6.48 \%)$ were most frequently stated anxieties of non-blood donors (Fig. 2b).

Preferred channels which should be used for blood donation campaigns were comparable between blood donors and non-blood donors (Fig. 3). Based on the answers, Instagram (blood donors: $66.84 \%$ / non-blood donors: 58.13\%), free TV (blood donors: 65.93\% / non-blood donors: 56.88\%), billboards (blood donors: $50.00 \% /$ non-blood donors:
51.04\%) and radio (blood donors: 48.35\% / non-blood donors: $52.29 \%$ ) should be predominantly used to promote blood donation.

\section{Discussion}

The results of this study indicate factors influencing the blood donation status in Germany as well as anxieties and reasons related to be (non-)blood donor. Strongest variable negatively influencing blood donation status was anxiety, whereas blood donors within family and friends was strongest variable to positively influence blood donation status.

In contrast to previous studies showing that women are more likely to be blood donors $[6,7]$, males were nonsignificantly more likely to be blood donors in the present study. The discrepancy compared to other studies might be related to the mean age of 31.8 years of the participants in this study. This mean age coincides with the mean age of women giving birth in Germany (31.5 years) according to the data of the Federal Statistical Office [11]. Additionally, up to $16 \%$ of female non-blood donors stated that pregnancy and breastfeeding is preventing them from donation. The present study also shows that the own health status is a strong determinant for blood donation status. Study participants with pre-conditions and lower HrQoL were less likely to be blood donors (Table 2). Similar findings were reported by Suen et al. (2020) and regarding satisfaction with the own health also by Studte et al. (2018) [6,7].
Figure 1 Reasons for blood donors to donate blood

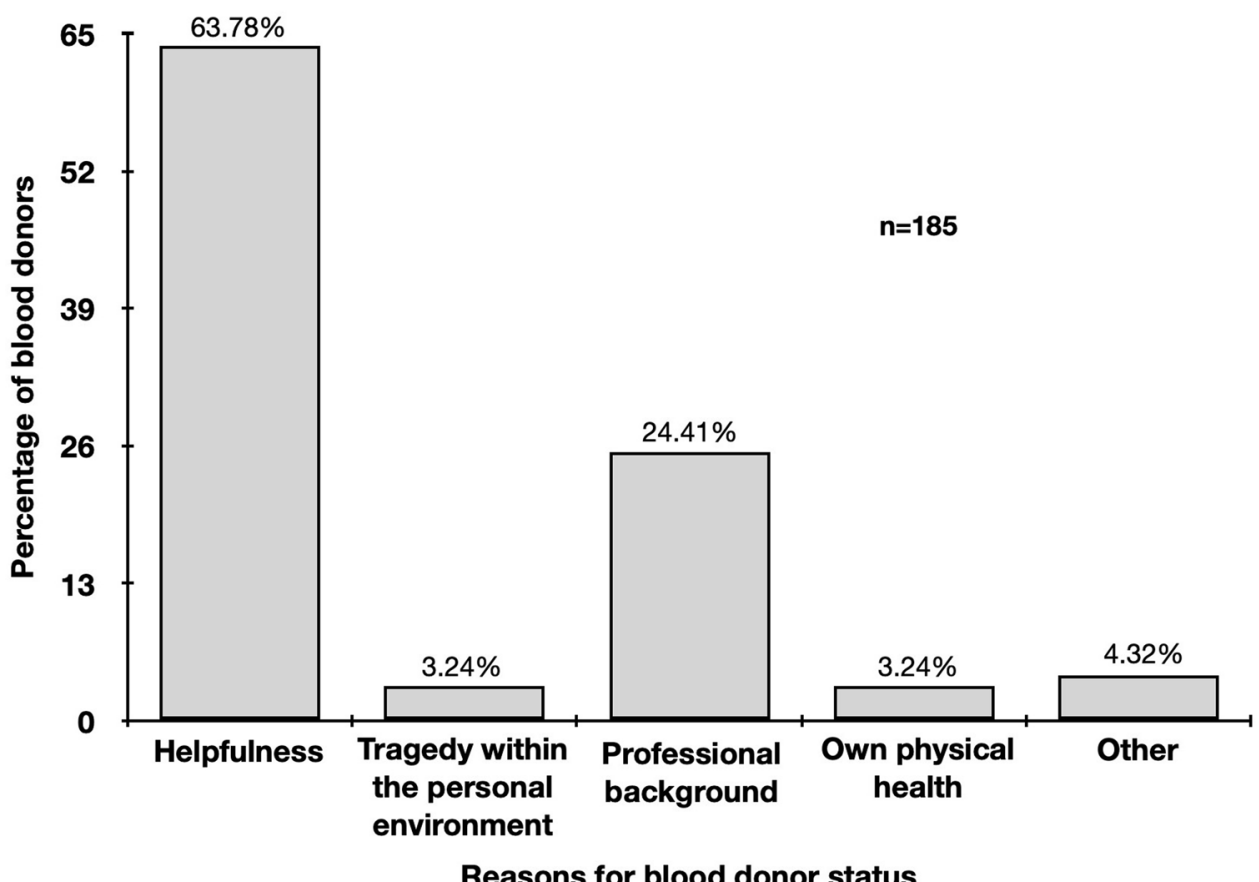

Reasons for blood donor status 


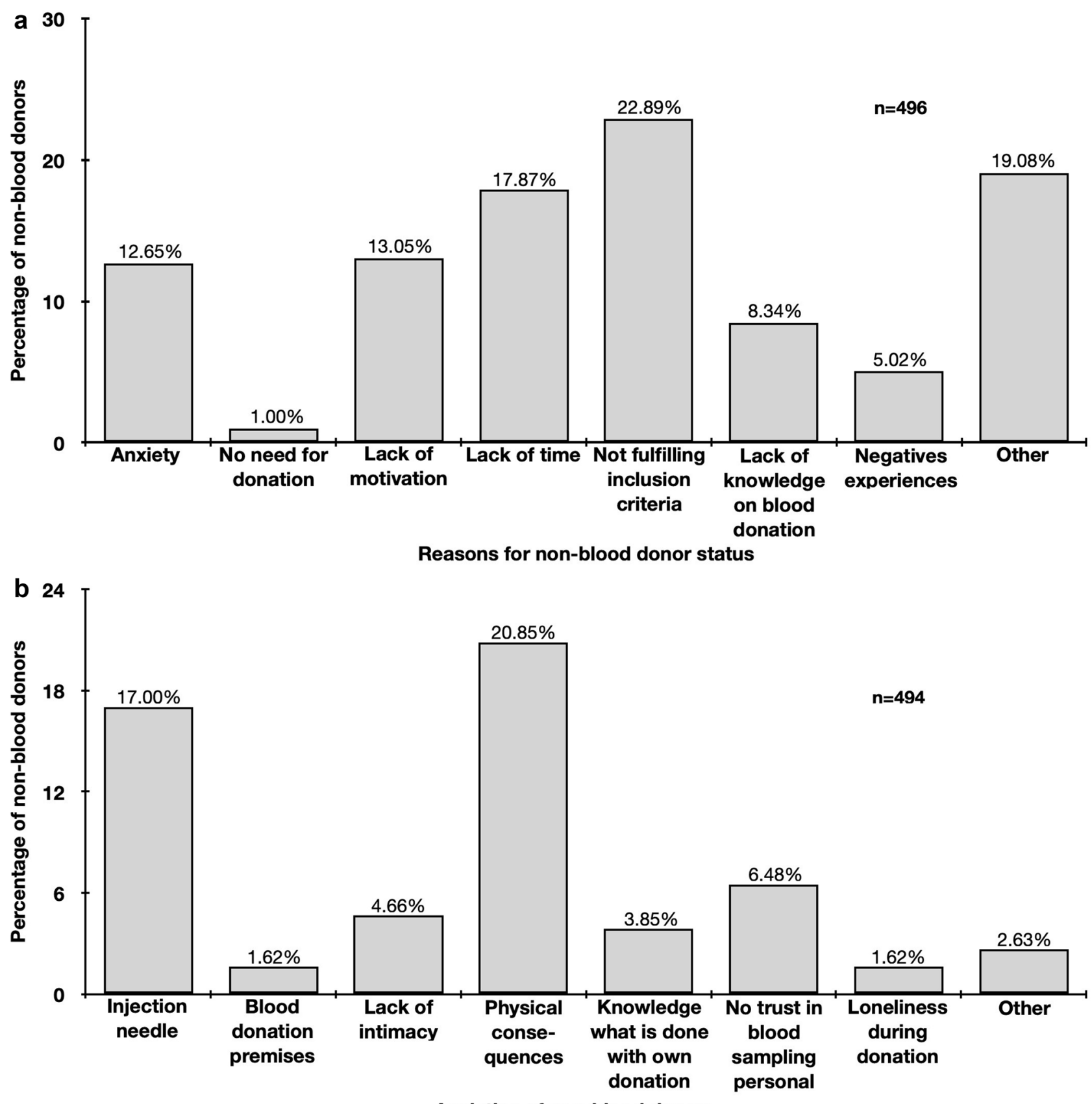

Anxieties of non-blood donors

Figure 2 Reasons for non-blood donors for not donating blood (a) and anxieties of non-blood donors related to blood donation (b). Multiple responses were allowed

Important and in line with previous data is that organ donors are more likely to be blood donors [6]. A study by Ferguson et al. (2012) identified that in contrast to non-blood donors, blood donors are more often altruistically motivated and satisfied by helping others (warm glow giving) [12]. The results of the present study reveal that more than $60 \%$ of blood donors stated helpfulness as reason for being blood donor. Therefore, it is assumable that organ donors are driven by similar reasons and it is not surprising that the number of blood donors is higher among organ donors compared to non-organ donors. Nevertheless, focusing on organ donors for the recruitment of new blood donors could be a strategy to increase the number of blood donations. This could be realized by joint organ and blood donor campaigns.

Further potential possibilities to recruit new blood donors are within the personal environment of current donors, since having blood donors within family and friends was strongly associated with being blood donor. Study participants with 


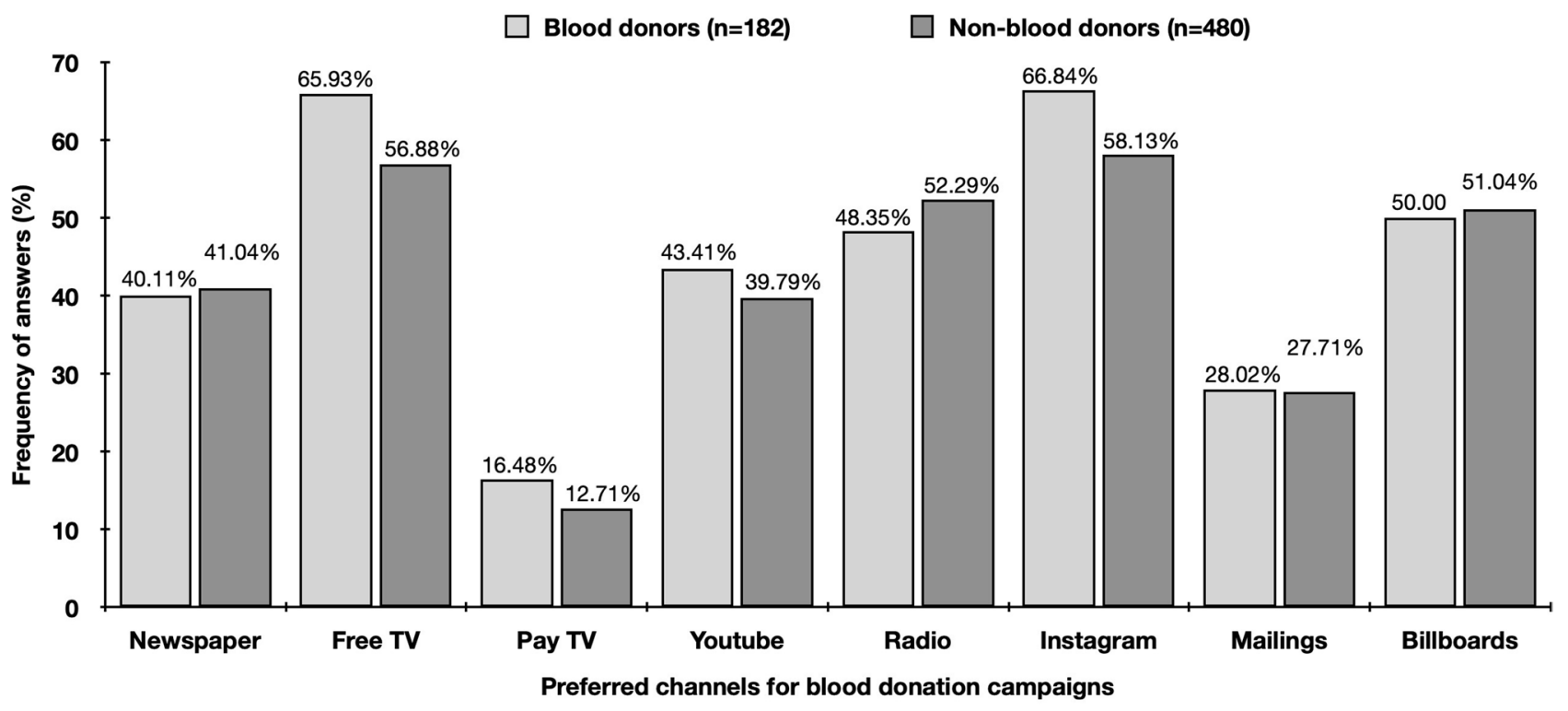

Figure 3 Preferred channels to promote blood donation campaigns. Multiple responses were allowed

blood donors within family, friends or both family and friends were 2.8, 2.4 and 5.1 times more likely to be blood donors, respectively. Future blood donation campaigns should focus more on the personal environment of blood donors and might even engage current blood donors into campaigns by providing them tailored information material for their relatives and / or friends. In addition, and due to the fact that blood donors had an average age of 21.8 years at first blood donation, social media channels such as Instagram could be more intensively used for the promotion of blood donation campaigns. Especially, since $58.13 \%$ of non-blood donors mentioned Instagram and 39.79\% Youtube as preferred channel for the promotion of blood donation.

Based on our data, education on blood donation is highly important. Unsurprisingly, participants with less knowledge on blood donation were more often non-blood donors. In contrast, participants knowing that blood donation is associated with health benefits were more likely to be blood donors. Of course, one has to keep in mind that blood donors have more knowledge due to their experiences with blood donation. Nevertheless, these findings on the influence of knowledge on blood donation status are supported by the study of Suen et al. (2020) from Hong Kong with a total of 542 participants [6]. Education is important to reduce anxieties, to educate that blood donation is not linked to tremendous physical consequences and to gain more trust in blood donation services. To be mentioned here is, that data from Italy indicates that blood donors have a lower risk for hospitalization, infectious disease or diseases related to the endocrine and blood system [13], respectively. A study from Finland showed that blood donors reveal an $88 \%$ lower risk of myocardial infarction compared to non-blood donors [14]. Examples for known negative physical effects related to blood donation are syncope, local bleeding, feeling tired, vertigo / dizziness or a diminished physical capacity [15, 16]. Nevertheless, positive physical effects of blood donation could be stronger integrated into campaigns in Germany. A potential focus of campaigns might be set on the potentially positive effects of blood donation on cardiovascular (CV) diseases, since $\mathrm{CV}$ diseases were the main cause of death in Germany in 2018 [17].

Interestingly, anxiety was strongly associated with being non-blood donor (Table 2), but anxiety was not the most frequently mentioned reason to not donate blood (Fig. 2a). We assume that this is due to the high number of study participants stating not fulfilling the criteria, having pre-conditions or a lack of time as reason for not donating blood. These participants presumably never thought about anxieties related to blood donation, because these other reasons already prevent them from donating. A study from Pakistan revealed that people with adequate knowledge were not donating blood if there is a lack of facilities and approaches [18]. This also indicates that besides knowledge, the availability of blood donation services is important and almost $18 \%$ of non-blood donors mentioned they are not having enough time to donate blood.

It is known that several regions reported a decrease in blood donations during SARS-CoV-2 pandemic [19, 20]. Since the study period was during the pandemic, we cannot exclude that the pandemic had an influence on our study sample. Due to the fact that older people and people with comorbidities are more vulnerable to severe COVID-19 
cases [21], it is likely that more young and healthier people were current blood donors and participated in our study. In addition, the cancellation of medical procedures or less injuries due to the lockdown reduced the demand on blood products $[19,20]$. This in turn might have influenced the blood donation behavior of potential study participants. Therefore, the previously mentioned aspects could have led to a recruitment bias and an influence on our analysis.

Despite the limitation related to the SARS-CoV-2 pandemic this study has further limitations, which will be discussed below.

First, the study was performed using an online survey and in terms of truthfulness of the answers we had to rely on the participants.

Second, the snowball system might have biased the recruitment of study participants. People in social environments may indicate similar characteristics, which in turn could have had an impact on the univariate analyses. Nevertheless, to recruit an adequate number of blood donors the access to the survey was also distributed using the Bavarian Red Cross.

Third, the mean age of the participants was relatively low with 33.4 years and therefore, the results might not represent the whole age range of people allowed to donate blood.

Fourth, our study only included a limited number of potential factors influencing blood donation status. More and broader studies are needed to obtain a complete overview of factors impacting the blood donation status.

Fifth, to assess HrQoL and knowledge of study participants on blood donation numerical scales were used, which provide less information compared to other instruments. Nevertheless, rating scales can be answered within a minimum of time and they are frequently used to assess HrQoL or severity of pain $[9,22]$.

\section{Conclusions}

This study reveals that family and friends and being an organ donor are strong drivers to become blood donor. In addition, blood donors indicated more knowledge on blood donation and in particular on the physical benefits of donating blood. In contrast, anxiety (e. g. on physical consequences) and preconditions are strong drivers to be a non-blood donor. Based on our data, future blood donation campaigns could strongly consider and implement the following aspects: (1) blood donors should be involved into campaigns, e. g. by providing them special information materials to recruit their relatives and friends, (2) materials should explain potential effects of blood donations on physical health, but in particular provide more knowledge on potential physical benefits, (3) campaigns need to have a stronger focus on young adults below 25 years and (4) on social media channels, respectively.
Acknowledgement We want to thank all study participants and the Bavarian Red Cross.

Funding Open Access funding enabled and organized by Projekt DEAL.

\section{Declarations}

Ethics approval This study was performed in accordance with the ethical standards as laid down in the 1964 Declaration of Helsinki and with the national legislation on data protection. Due to the nature of the study, which represents a voluntary online survey of a non-vulnerable population, asking non-stigmatizing questions, an ethical approval was not necessary.

Informed consent All participants gave fully informed consent to participate in this study.

Conflict of interest BS declares to have no conflict of interest. LM is former employee of UCB Pharma $\mathrm{GmbH}$ and received consultancy and speaker fees from UCB Pharma GmbH.

Open Access This article is licensed under a Creative Commons Attribution 4.0 International License, which permits use, sharing, adaptation, distribution and reproduction in any medium or format, as long as you give appropriate credit to the original author(s) and the source, provide a link to the Creative Commons licence, and indicate if changes were made. The images or other third party material in this article are included in the article's Creative Commons licence, unless indicated otherwise in a credit line to the material. If material is not included in the article's Creative Commons licence and your intended use is not permitted by statutory regulation or exceeds the permitted use, you will need to obtain permission directly from the copyright holder. To view a copy of this licence, visit http://creativecommons.org/licenses/by/4.0/.

\section{References}

1. GBE. Production of blood and blood components (number and rate). Classification: years, Germany, blood donations. Primary source: Bericht zur Meldung nach $\S 21$ Transfusionsgesetz, Paul EhrlichInstitut. In www.gbe-bund.de (path of search: Home $>$ Health Care System $>$ Medical Processes, Medical Examinations and Therapies $>$ Blood donation, Blood transfusion $>$ Table (ad hoc): Blood donations, production). 2020. Accessed 15 September 2020.

2. Ferguson E. Predictors of future behaviour: a review of the psychological literature on blood donation. Br J Health Psychol. 1996;1:287-308.

3. Simon TL. Where have all the donors gone? A personal reflection on the crisis in America's volunteer blood program. Transfusion. 2003;42:273-9.

4. Greinacher A, Weitmann K, Schönborn L, Alpen U, Gloger D, Stangenberg W, Stüpmann K, Greger N, Kiefel V, Hoffmann W. A population-based longitudinal study on the implication of demographic changes on blood donation and transfusion demand. Blood Adv. 2017;1(14):867-74. https://doi.org/10.1182/ bloodadvances.2017005876.

5. Seifried E, Klueter H, Weidmann C, Staudermaier T, Schrezenmeier H, Henschler R, Greinacher A, Mueller MM. How much blood is needed? Vox Sanguinis. 2011;100:10-21. https:// doi.org/10.1111/j.1423-0410.2010.01446.x. 
6. Suen LKP, Siu JY-m, Lee YM, Chan EA. Knowledge level and motivation of Hong Kong young adults towards blood donation: a cross-sectional survey. BMJ Open 2020;10:e031865. https://doi. org/10.1136/bmjopen-2019-031865.

7. Studte S, Clement M, Soliman M, Boenigk S. Blood donors and their changing engagement in other prosocial behaviors. Transfusion. 2019;59(3):1002-15. https://doi.org/10.1111/trf.15085.

8. SoSci Survey Online Tool, https://www.soscisurvey.de.

9. Parkin D, Rice N Jacoby A, Doughty J. Use of a visual analogue scale in a daily patient diary: modelling cross-sectional time-series data on health-related quality of life. Soc Sci Med. 2004;59:341360. https://doi.org/10.1016/j.socscimed.2003.10.015.

10. JASP Team. JASP (Version 0.13.1) [Computer software]. 2020.

11. DESTATIS. Daten zum durchschnittlichen Alter der Mutter bei Geburt insgesamt und 1. Kind nach Bundesländern. 2020. https:// www.destatis.de/DE/Themen/Gesellschaft-Umwelt/Bevoelkerung/ Geburten/Tabellen/geburten-mutter-alter-bundeslaender.html. Accessed 15 September 2020.

12. Ferguson E, Taylor M, Keatly D, Flynn N, Lawrence C. Blood donors' helping behavior is driven by warm glow: more evidence for the blood donor benevolence hypothesis. Transfusion. 2012;52(10):2189-200. https://doi.org/10.1111/j.1537-2995.2011.03557.x.

13. Gallerani M, Volpato S, Cellini M, Reverberi R, Mikhailidis DP, Manfredini R. Risk of illness, hospitalization and death in a cohort of blood donors in Italy. Curr Med Res Opin. 2014;30(9):1803-12. https:// doi.org/10.1185/03007995.2014.921146.

14. Salonen JT, Tuomainen TP, Salonen R, Lakka TA, Nyyssönen K. Donation of Blood Is Associated with Reduced Risk of Myocardial Infarction: The Kuopio Ischaemic Heart Disease Risk Factor Study. Am J Epidemiol. 1998;148:445-51.
15. Newman BH. Donor reactions and injuries from whole blood donation. Transfus Med Rev. 1997;11:64-75.

16. Sojka BN, Sojka P. The blood-donation experience: perceived physical, psychological and social impact of blood donation on the donor. Vox Sanguinis. 2003;84:120-8.

17. DESTATIS. Zahl der Todesfälle im Jahr 2018 um 2,4\% gestiegen. 2020. https://www.destatis.de/DE/Themen/Gesellschaft-Umwelt/ Gesundheit/Todesursachen/todesfaelle.html. Accessed 15 Sept. 2020.

18. Bilal M, Haseeb A, Zahid I, Lashkerwala SS, Saeeduddin F, Saad M, Arshad MH, Moorpani M, Khan MZ, Tariq A, Habib H, Islam T, Advani R. Knowledge, Attitudes and Perceptions Among NonBlood Donor Female Health Care Professionals. Glob J Health Sci. 2016;8(4):203-11. https://doi.org/10.5539/gjhs.v8n4p203.

19. Yahia AIO. Management of blood supply and demand during the COVID-19 pandemic in King Abdullah Hospital, Bisha, Saudi Arabia. Transfus Apher Sci. 2020;59:102836. https://doi. org/10.1016/j.transci.2020.102836.

20. Al-Riyami AZ, Abdella YE, Badawi MA, et al. The impact of COVID-19 pandemic on blood supplies and transfusion services in Eastern Mediterranean Region. Transfus Clin Biol. 2020;S12467820(20):30161. https://doi.org/10.1016/j.tracli.2020.11.002.

21. van Gerwen M, Alsen M, Little C, Barlow J, Genden E, Naymagon L, et al. Risk factors and outcomes of COVID-19 in New York City: a retrospective cohort study. J Med Virol. 2021;93:907-15. https:// doi.org/10.1002/jmv.26337.

22. Williamson A, Hoggart B. Pain: a review of three commonly used pain rating scales. J Clin Nursing. 2005;14:798-804. 